
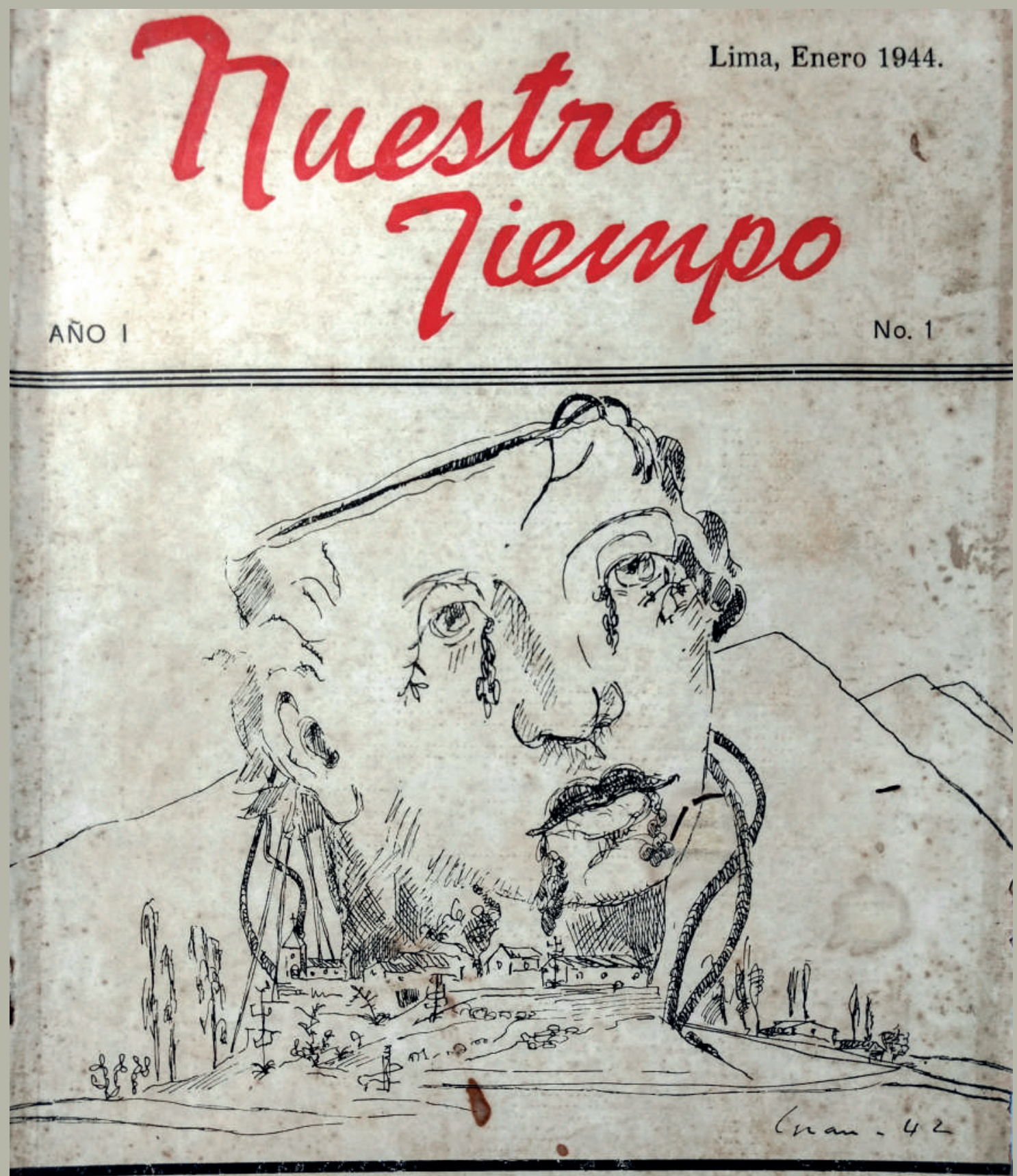

REVISTA PARA LA DEFENSA DE LA CULTURA 


\title{
Nuestro Tiempo (1944): un proyecto de renovación pictórica y cultural en Lima ${ }^{1}$
}

\author{
Zandor Emerson Zarria \\ Universidad Nacional Mayor de San Marcos \\ zzarria@gmail.com \\ Lima-Perú
}

\begin{abstract}
Resumen
La presente investigación se propone revisar la trayectoria de la revista Nuestro Tiempo (1944), publicación que cumplió un rol significativo en la renovación de las ideas sobre la pintura en el entorno cultural limeño de los años cuarenta. Considerando que no existen trabajos que desarrollen el itinerario de esta revista, ${ }^{2}$ nuestro objetivo es presentar una primera propuesta crítica que presente sus características más importantes, así como sus objetivos editoriales, los cuales comentaremos, siempre teniendo en cuenta el contexto histórico de la época y la situación del entorno cultural en la Lima de entonces. Nos interesa analizar algunos aspectos específicos que destacan en Nuestro Tiempo: 1) el debate y discusión sobre el arte pictórico que la revista intenta fomentar a través de artículos y encuestas; 2) la promoción de los nuevos representantes de la plástica local, cuya presencia se destaca para manifestar la dirección que deben tomar los artistas modernos peruanos; 3) el rol de la revista en la animación y producción cultural en la ciudad; 4) el papel del crítico, ensayista y dramaturgo Juan Ríos en esta publicación; 5) la configuración de Nuestro Tiempo como plataforma modernizadora y, finalmente, 6) la posición de la revista frente a la situación política que vive el país en el contexto mencionado.
\end{abstract}

Palabras clave: revista, pintura, arte independiente, resistencia cultural, plataforma modernizadora, proyecto intelectual, libertad de prensa, autoritarismo, producción cultural

\begin{abstract}
This research aims to review the trajectory of the magazine Nuestro Tiempo (1944), a publication that played a significant role in the renewal of ideas about painting in Lima's cultural environment in the 1940 s. Considering that there are no works that develop the itinerary of this magazine, our objective is to present a first critical proposal that presents its most essential characteristics, as well as its editorial objectives, which we will comment on, always taking into account the historical context of the time and the situation of the cultural environment in Lima at that time. We are interested in analyzing some specific aspects that stand out in Nuestro Tiempo: 1) The debate and discussion on pictorial art that the magazine tries to encourage through articles and surveys. 2) The promotion of the new representatives of the local plastic arts, whose presence is highlighted to show the direction that modern Peruvian artists should take. 3) The role of the magazine in the animation and cultural production in the city. 4) The role of the critic, essayist, and playwright Juan Rios in this publication. 5) The configuration of Nuestro Tiempo as a modernizing platform and, finally. 6) The position of the magazine in the face of the political situation that the country is experiencing in the mentioned context.
\end{abstract}

Keywords: magazine, painting, independent art, cultural resistance, modernizing platform, intellectual project, press freedom, authoritarianism, cultural production

1 La presente investigación constituye una versión ampliada de la ponencia "Renovación pictórica y cultural en Lima: el caso de la revista Nuestro Tiempo (1944)", que ofrecí en el Tercer Congreso Internacional de Arte Peruano, celebrado en el Instituto Cultural Peruano Norteamericano (Lima) en noviembre de 2019.

2 Sobre esta publicación no existen trabajos críticos, salvo un párrafo que le dedica Manuel Pantigoso en su estudio "La generación literaria del 30-36" (1998). Después, las referencias a Nuestro Tiempo solo constituyen menciones breves, sobre todo cuando se alude al crítico y dramaturgo Juan Ríos. 


\section{Ideas, revistas y contexto cultural en Lima entre 1936 y 1945}

Debemos recordar que, luego del abrupto final del Gobierno de Augusto Bernardino Leguía (1919-1930), el Perú ingresó en un periodo de alta conflictividad social: el tercer militarismo (Jorge Basadre) no solo supuso una etapa de la vida del país en la que el poder oligárquico se enfrentó directamente con las agrupaciones políticas de izquierda (el APRA y el Partido Comunista, principalmente), que buscaban las reivindicaciones sociales tanto tiempo negadas, sino que las libertades cívicas y de expresión fueron duramente suprimidas. Además, el interés por las instituciones y plataformas de producción cultural decaerá considerablemente, sobre todo durante el periodo de Gobierno del mariscal Óscar R. Benavides, cuya relación con las expresiones culturales per se será por demás conflictiva: las deportaciones a políticos e intelectuales, así como la confiscación de publicaciones (revistas y libros) será una seña reconocible de este Gobierno.

No debemos olvidar tampoco que, entre 1932 y 1935, fueron clausuradas las actividades académicas de la universidad San Marcos (importante polo intelectual y de crítica social en Lima durante la primera mitad del siglo XX) debido a la alta convulsión política que vivía el país. Asimismo, la segunda mitad de los años treinta puede considerarse como un periodo en que las ideologías autoritarias, acicateadas por la influencia de los totalitarismos europeos, pudieron campear en algunos sectores de las clases dominantes del país, amparadas en los gestos del presidente Oscar R. Benavides. ${ }^{3}$

No obstante este contexto político, a todas luces desalentador, la relación entre la producción cultural y la sociedad civil comenzará a cambiar hacia fines de la década de 1930: no solo el país será sede de la VIII Conferencia Interamericana, sino que aparecerá la Orquesta Sinfónica Nacional e instituciones culturales como Ínsula, la Asociación de Artistas Aficionados, el Instituto Cultural Peruano Norteamericano y la Asociación Nacional de Escritores y Artistas. Del mismo modo, luego de los oscuros primeros años de esa década, empezará a incrementarse el número de revistas culturales que, de alguna manera, intentan combatir la forma unívoca de concebir la cultura que las élites del país, a través de sus medios de comunicación (El Comercio, La Prensa o La Crónica), intentan difundir en el imaginario político peruano. Algunas de estas revistas son, por citar un ejemplo, Palabra. En defensa de la Cultura (1936-1944), el boletín CADRE (1936-1937), El Uso de la Palabra (1939), Tres (1939-1941) e Historia (1943-1945), sin olvidar que existían también otras publicaciones culturales de carácter más bien conservador, al menos en sus primeros años: Sphynx, Mercurio Peruano, Cultura Peruana y Turismo son algunas de ellas. Todo este panorama irá modificándose con mayor evidencia en el Gobierno de Manuel Prado (1939-1945) hasta alcanzar su mayor despliegue en 1945, año de la victoria de los Aliados en la Segunda Guerra Mundial e inicio del periodo democrático de José Luis Bustamante y Rivero (1945-1948).

Ahora, es importante considerar algunos aspectos del panorama político en estos años. 1939 es año de elecciones y reapertura democrática. Manuel Prado Ugarteche (1939-1945) inicia su Gobierno e intenta desligar al Perú de sus antiguas adhesiones a las potencias del Eje. Su fuerte acercamiento al Gobierno de Franklin Roosevelt, dentro de la política del "buen vecino", permitió amainar las protestas de los grupos de izquierda como el APRA y el Partido Comunista (Cotler, 1987, pp. 254-258), aunque estos

3 En el Perú, los años del Gobierno de Benavides y el periodo correspondiente a la Segunda Guerra Mundial evidencian un desencuentro entre las manifestaciones libres de la cultura y las prácticas de control político ejercidas por las autoridades estatales. Solo por citar un ejemplo, recordemos lo que Estuardo Núñez (1994) anota al respecto: "Un ciclo de charlas sobre poesía peruana que organizamos y fue aceptado e inaugurado por Radio Nacional del Perú en abril de 1937, fue bruscamente cancelado por orden directa del Mariscal gobernante que no transigía en oír la mención de Manuel González Prada, aunque se tratase sólo de su obra poética” (p. 123). 
continuaran proscritos. Se incrementó también el número de organizaciones sindicales y fueron esfumándose las señas que vinculaban al Estado con las potencias totalitarias europeas. Se inició así un periodo que Julio Cotler ha calificado de "tranquilidad política". Aunque estas afirmaciones supongan un cambio de dirección, es evidente que el ejercicio de una cultura democrática plena aún no se concreta. Prueba de ello es que durante todo el periodo de Prado se encuentra vigente la Ley 9034, promulgada por Benavides en sus últimos días como gobernante; esta ley instituía requisitos para publicar periódicos, disponía derechos de rectificación y establecía posibles sanciones que incluían desde multas hasta incautaciones de imprenta (Gargurevich, 1991).

Esto es fundamental para entender por qué, en esos años, se vive una renovación política que, sin embargo, dista aún de concretar una sociedad en la que las libertades de participación política y expresión, así como las prácticas culturales inclusivas (que busquen nuevas formas de comprender la literatura, el derrotero del arte pictórico y las tradiciones culturales que conforman la identidad peruana), aún no tienen mucha presencia y comienzan, por ello, a emerger nuevamente, aunque todavía a un ritmo más bien lento. Como ya habíamos afirmado, el clima cultural empezará a acrecentarse y, en 1940, ya existen en Lima centros como el Instituto Cultural Peruano Norteamericano (IPNA), la Asociación Nacional de Escritores y Artistas del Perú (ANEA), la sociedad Entre Nous, la Asociación de Artistas Aficionados (AAA), el Instituto Bach y la asociación cultural Ínsula. Todas ellas permitirán el desarrollo de conferencias, exposiciones de arte y el intercambio de ideas. ${ }^{4}$

2. Nuestro Tiempo: revista de renovación pictórica y cultural

Aparecida en enero de 1944, Nuestro Tiempo se planteó como una revista bimestral y tuvo

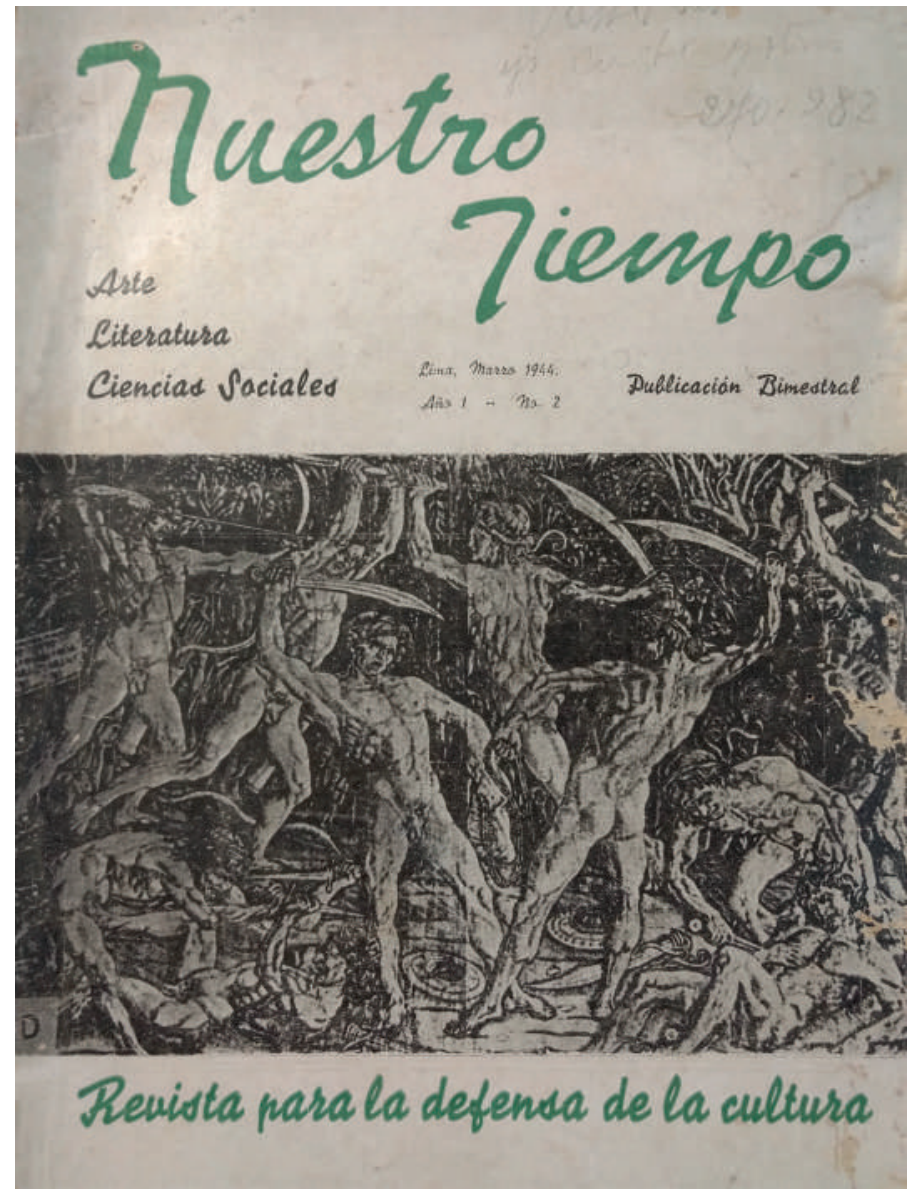

Imagen 2. Portada de la revista Nuestro Tiempo. Revista para la defensa de la cultura. Número 2. Marzo de 1944.

4 Una práctica usual durante la época es leer una conferencia que luego será publicada, a modo de artículo, en una revista (podemos mencionar como ejemplo el caso de 3, cuya gran cantidad de ensayos habían sido leídos en las instituciones ya mencionadas). 
como consejo de redacción a Juan Ríos, Xavier Abril, Raúl María Pereyra (este último, adherido recién en el segundo número) y Fernando Hernández de Aguiero, el cual aparecía, además, como director. Tenemos conocimiento de que la revista publicó tres números, correspondientes a los meses de enero, marzo y mayo de $1944,{ }^{5}$ aunque, luego de agotar todos los recursos bibliográficos disponibles en Lima, ${ }^{6}$ solo hemos podido tener acceso a los dos primeros. Por esa razón, queremos confirmar que nuestro trabajo constituye, como lo indicamos en el resumen anterior, una primera aproximación, la cual, esperamos, será completada, toda vez que en el futuro podamos acceder al tercer número de Nuestro Tiempo. ${ }^{7}$

El nombre completo de la revista fue Nuestro Tiempo. Revista para la defensa de la Cultura, denominación que resulta sintomática del periodo en que se vive: una época en que las manifestaciones culturales y la expresión política y cívica han sido severamente reducidas por el poder estatal y las clases dominantes. En ese sentido, el subtítulo "Revista para la defensa de la Cultura" constituye un rótulo de protesta y resistencia, como se evidencia en los nombres de otras revistas del mismo contexto: Palabra. En defensa de la Cultura (19361944) o Historia. Revista Peruana de Cultura (1943-1945). ${ }^{8}$

Nuestro Tiempo nació como una plataforma de discusión sobre el derrotero del arte plástico en el Perú. Aunque en sus páginas también se abordaron temas de economía, política y literatura, parece ser la tradición pictórica peruana (y su senda futura) la apuesta de esta revista. Como tantos proyectos intelectuales de la época, Nuestro Tiempo intenta bregar en la sociedad peruana e inyectarle la suficiente dosis de cultura necesaria en un contexto en el que las clases medias y los círculos intelectuales demandan un orden más libre y democrático (lo que se consolidará, por supuesto, con la victoria de Bustamante y Rivero):

Por encima de inevitables discrepancias de detalle, une a sus redactores una esencial emoción contemporánea y un mismo sentido de la Dignidad del Hombre y de la Defensa de la Cultura. Convencidos de que la verdadera armonía surge del libre juego de las ideas, pretendemos fundar un órgano de análisis independiente y de polémica noble, en donde tendrá vasta cabida la palabra de todos aquellos que[,] ajenos a nuestra Revista[,] tengan algún punto que plantear o debatir (Nuestro Tiempo, 1944a, p. 1).

La defensa de la cultura y la libertad es un derrotero claro para esta revista que, sin estar ligada a institución alguna, pudo publicar páginas destacables y con una cantidad de información no desdeñable: ensayos sobre arte peruano, artículos o reseñas sobre exposiciones

5 Gracias a los apuntes de Juan Ríos (1993) en su diario personal, sabemos que se tenía previsto un cuarto número, como atestigua una entrada de su diario correspondiente a junio de 1944. Desafortunadamente, el número nunca se publicó y, meses después, en octubre del mismo año, Ríos reconoce que Nuestro Tiempo no volverá a ver la luz (pp. 71-93).

6 Esta investigación se realizó cuando era posible acceder a archivos y bibliotecas de Lima, antes de que el Perú se viera afectado por la pandemia debida al COVID-19.

7 Luego de visitar todos los repositorios bibliográficos y hemerográficos de Lima, solo hemos podido encontrar dos de los tres números de Nuestro Tiempo en la Biblioteca Manuel Solari Swayne del Museo de Arte de Lima. Las noticias acerca del tercer número las hemos encontrado en el estudio "La generación literaria del 30-36" de Manuel Pantigoso y en el diario personal de Juan Ríos.

8 Palabra, la cual nació como un símbolo de la defensa de la democracia y en abierta oposición a las prácticas autoritarias y fascistas, fue fundada y editada por Augusto Tamayo Vargas, José Alvarado Sánchez, José María Arguedas, Emilio Champion y Alberto Tauro. La revista significó una apertura a voces nuevas (entre ellos, Juan Ríos, importante figura de Nuestro Tiempo) y algunas ya renombradas como Jorge Basadre, Carlos Cueto Fernandini, César Miró, Xavier Abril (futuro editor de Nuestro Tiempo), Alfonso de Silva, Luis Cernuda, Rafael Alberti, Jean Cassou y Pablo Picasso. Historia fue una publicación académica y progresista dirigida por Jorge Basadre en los últimos años del primer Gobierno de Prado; se trata de una plataforma que no solo discurre sobre temas históricos, sino que ejerce el rol de discutir la actualidad política y cultural del país, así como de la Europa convulsionada por la guerra. Destaca su naturaleza abierta al debate y su permanente consigna de libertad. 
recientes, encuestas a pintores nacionales, poemas, relatos, antologías de poesía, reflexiones sobre la arquitectura peruana, el panorama musical y películas proyectadas en Lima, etc. ${ }^{9}$ Entre sus redactores más usuales podemos citar a Juan Ríos, Rodolfo Holzmann, Fernando Hernández de Aguiero, Xavier Abril, Pedro Salinas, Hans Valdemar y Raúl María Pereira. También se encuentran publicados textos y poemas de Benedetto Croce, Jorge Eduardo Eielson, ${ }^{10}$ Rafael Alberti, César Vallejo y Pablo Neruda.

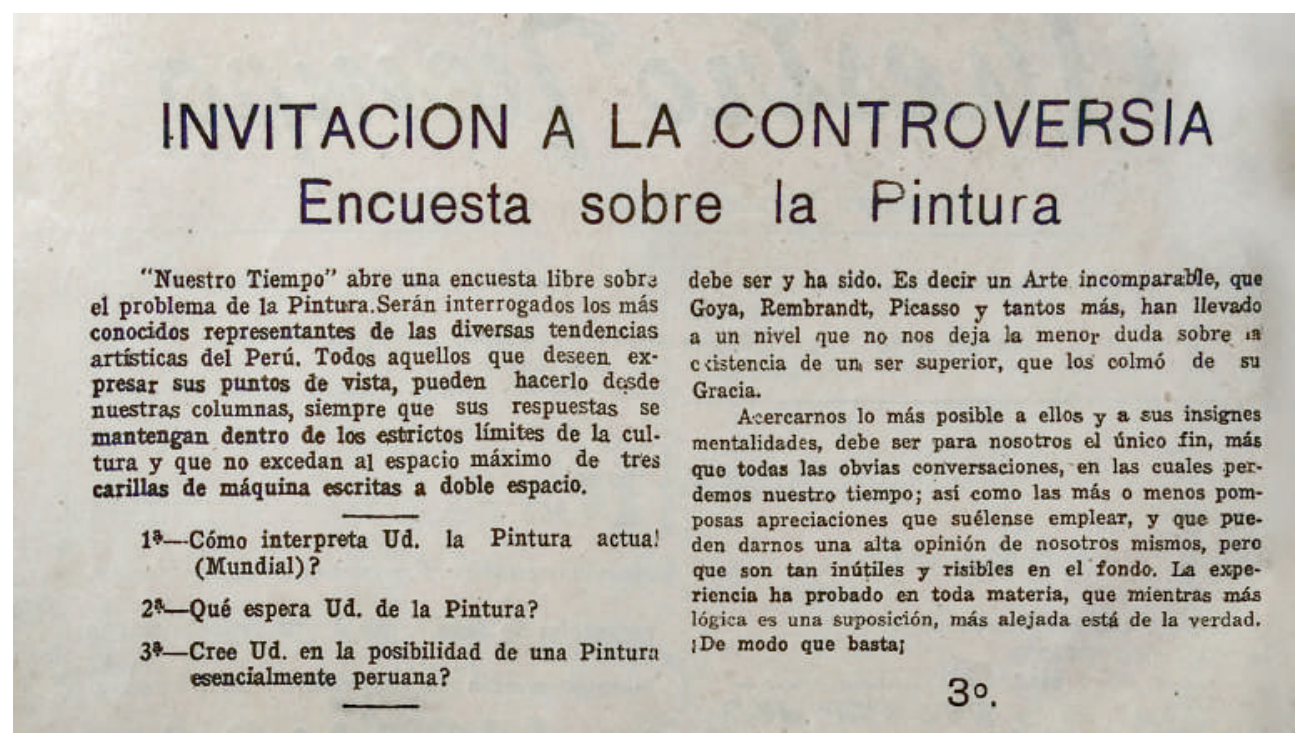

Imagen 3. Sección correspondiente al texto "Invitación a la controversia. Encuesta sobre la Pintura”. Nuestro Tiempo. Número 1. Enero de 1944. Página 2.

Quisiéramos destacar que Nuestro Tiempo constituye la primera publicación no institucional cuyo contenido está dedicado, en gran parte, a discutir el arte pictórico de la época; no solo es una revista cultural que presta atención ocasional al arte, sino una plataforma interesada en reflexionar sobre la naturaleza de la pintura peruana y el horizonte que esta debe tener, además de interesarse por los nuevos valores (representantes) de la plástica local. Este interés por la pintura y su naturaleza se observa en los dos números de la revista, pues ambos inician sus páginas con la sección "Invitación a la controversia. Encuesta sobre la Pintura", en la que se invita a distintos artistas ya reconocidos a plantear sus opiniones sobre el tema a partir de tres preguntas breves: 1) ¿Cómo interpreta usted la pintura actual (mundial)?, 2) ¿Qué espera usted de la pintura? y 3) ¿Cree usted en la posibilidad de una pintura esencialmente peruana? Los artistas convocados en esta encuesta van desde el máximo exponente del indigenismo, José Sabogal, hasta pintores que abogan por una estética más cosmopolita y cercana al arte independiente, como Ricardo Grau o Carlos Quizpez Asín. En total, se obtienen ocho respuestas, algunas más largas que otras, correspondientes a los siguientes artistas y críticos peruanos: 1) Ricardo Grau, 2) Sérvulo

9 Consideramos valiosa la información sobre exposiciones artísticas que, en sus páginas, presenta Nuestro Tiempo. Su revisión serviría para empezar a trazar las coordenadas del panorama de los artistas plásticos vigentes en la Lima de los primeros años de la década de 1940.

10 Resulta interesante mencionar que, en el número 2 de Nuestro Tiempo, aparece el poema de Jorge Eduardo Eielson titulado "Nocturno de la tierra", primera versión del texto "Nocturno terrenal", que formará parte de su primer libro, Reinos, cuaderno de poemas que fuera publicado en el número 9 de la revista Historia en 1945. 
Gutiérrez, 3) José Sabogal, 4) Juan Manuel Ugarte Eléspuru, 5) Moisés Fuentes Ibáñez, 6) Carlos Quizpez Asín, 7) Carlos Raygada y 8) Carmen Saco. La importancia de estos nombres en la tradición pictórica de estos años revela el nivel de impacto que tendría una revista como la que estamos estudiando.

Aunque no disponemos de un espacio amplio para comentar los detalles de un debate de esta naturaleza, quisiéramos presentar dos casos de la encuesta mencionada, ${ }^{11}$ que ejemplifican bien la divergencia de opiniones y el rol de independencia que busca enarbolar Nuestro Tiempo. En primer lugar, enfoquémonos en las palabras de la escultora Carmen Saco (1944) quien, con una posición similar a la de José Sabogal, afirma lo siguiente: "Espero de la Pintura que refleje, cada vez más, y más intensamente, la protesta social, la esperanza revolucionaria de nuestro tiempo. Que sea la verdadera expresión de la lucha y de la agonía del hombre." (p. 4) Esta opinión se verá contrastada, no obstante, por la mayoría de los artistas convocados, quienes enjuician un arte que se encuentre supeditado a ideologías, a luchas políticas o a escenas costumbristas. Al respecto, Juan Manuel Ugarte Eléspuru (1944) responde:

Espero de la Pintura que deje de ser un agente de voluptuosidad objetiva y readquiera el sentido de trascendencia y alta espiritualidad que la nutrían en el Renacimiento y la Edad Media. Es decir que vuelva a ser un medio expresivo del hombre en conflicto consigo mismo y el mundo que lo rodea. Que vuelva a ser la voz del hombre hecha imágenes, su canto, su queja o su alarido. Entonces la pintura dejará de ser un capricho de dilettantes y será otra vez buscada, comprendida y amada por todos. Esto no quiere decir que se convierta en pintura de propaganda, al servicio de las banderías beligerantes. La Pintura no tiene por qué bajar a la calle como participante en las pasiones de la hora, pues tal actitud le impondría medios y fines que le son ajenos y perjudiciales (p. 5).

Estas palabras de Ugarte Eléspuru concilian más con un arte pictórico que dialogue con el hombre mismo y su mundo interior, un arte que provenga de una "alta espiritualidad", concepto que se aproxima a los términos utilizados por otros artistas encuestados, quienes vinculan la pintura con la "especulación metafísica", la "universalidad" y el carácter "moderno" del arte actual. Todas estas apreciaciones se acercan, por supuesto, a la tendencia del arte independiente, el cual, en los últimos años, estaba ganando la batalla a los indigenistas en el ámbito local. Recordemos que, en el terreno pictórico y también en el literario, las décadas de 1930 y 1940 van a modificar, en parte, los parámetros que guían la creación de las obras artísticas y literarias, sobre todo en lo que se refiere al "tema". En su ensayo "Bases sociales y circunstancias de la reaparición de un universalismo", Mirko Lauer explica con agudeza la relación entre el imperialismo norteamericano en el contexto socioeconómico peruano y el surgimiento del universalismo en las artes visuales y la literatura. Lauer (1976) sostiene que, ya en 1930, la economía peruana está dominada por el imperialismo norteamericano, motivo por el que la búsqueda de lo nacional es asumida ahora por un "principio ordenador extranjero"; asimismo, la burguesía reconoce un "ámbito cultural propio" (la ciudad, el mundo urbano) como la nueva fuente de creación: "el arte -como práctica y como medio humano- puede ser su propio sustento social y su propia tradición" (p. 124). Efectivamente, el arte con sustento ideológico y social ha perdido terreno, y una suerte de orientación universalista comienza a campear en el imaginario de algunos creadores peruanos:

No se trata ya de crear una imagen más ajustada del país, sino más bien de borrar toda imagen del país, o si se quiere, adecuarla a la nueva realidad económica que se vive. En

11 Gracias al artículo de Manuel Pantigoso, sabemos que esta encuesta presenta un análisis elaborado por Raúl María Pereira y titulado “Encuesta sobre la pintura. Balance de la encuesta”. El texto, sin embargo, fue publicado en el número 3 de la revista, por lo que su inaccesibilidad no nos permitirá, ahora, su ponderación y respectivo comentario. 


\section{NUESTRA EXPOSICION}

\section{Primer Salón de Pintura de "Nuestro Tiempo"}

De acuerdo con su declarada orientación po. lémica $y$ contemporánea, "NUESTRO TIEMPO" presenta, en los salones del Instituto Peruano-Norteamericano, su primera muestra de la pintura en el Perú. Afirmando los conceptos estéticos ya aceptados por todos los públicos cultos de Euro. pa y América, las obras seleccionadas tienen, con prescindencia del tema y del parecido fotográfi. co, un valor plástico intrínseco que basta para justificarlas. Porque la Pintura, lo repetimos, comienza donde terminan lo pintoresco, lo anecdótico y lo apteramente imitativo.

En su inirial manifestación artística "NUES. TRO TIEMPO" presenta: la luminosa fiesta pe. ruana de Jorge Vinatea Reinoso, el armonioso $y$ colorido ritmo de Carlos Quizpez Asin, la exquisita y matizada sensibilidad de Ricardo Grau, el intimo y delicado lirismo de Federico Reinoso, el expresivo y vigoroso impulso de Juan Manuel Ugarte Eléspuru, la recia y dramática intuición de Sérvulo Gutiérrez, y la sobria y humana sir ceridad de Sabino Springett.

Preside y honra nuestra exposición la obra de Jorge Vinatea Reinoso, en quien la amorosa delectación de lo peruano se unió siempre an espontánea pero esencial noción de la Pintura como Creación universal y libre. Los otros seis artistas escogidos, son los que, a nuestro juicio, caracterizan mejor en el Perú las actuales ten. dencias estéticas.

"NUESTRO TIEMPO" agradece al Instits to Peruano Norteamericano, a los expositores y a los propietarios de cuadros que, con su desinteresada colaboración, han hecho posible la res lización de esta primera muestra de conjunto de la Pintura Contemporánea en el Perú.

Imagen 4. Sección correspondiente al texto "Nuestra exposición. Primer Salón de Pintura de “Nuestro Tiempo"”. Nuestro Tiempo. Número 1. Enero de 1944. Página 10.

Esa enajenación ideológica, aunada a la influencia de las corrientes artísticas y literarias provenientes del extranjero (el arte no figurativo, la pintura abstracta, el surrealismo, el existencialismo en la literatura), será una constante de modernización del imaginario literario y artístico en la segunda mitad de los años cuarenta y gran parte de los años cincuenta. En ese sentido, se entiende por qué una revista como esta, aunque desea ser una tribuna de expresión libre, tiene ya una consigna y un voto sobre el derrotero de la pintura en el Perú: la apuesta por el arte independiente. Esto se hace más evidente con la exposición de pintura que organiza Nuestro Tiempo:

De acuerdo con su declarada orientación polémica y contemporánea, "NUESTRO TIEMPO" presenta, en los salones del Instituto Peruano-Norteamericano, su primera muestra de la pintura en el Perú. Afirmando los conceptos estéticos ya aceptados por todos los públicos cultos de Europa y América, las obras seleccionadas tienen, con prescindencia del tema y del parecido fotográfico, un valor plástico intrínseco que basta para justificarlas. Porque la Pintura, lo repetimos, comienza donde terminan lo pintoresco, lo anecdótico y lo apteramente imitativo (Nuestro Tiempo, 1944b, p. 10).

Resulta interesante que los términos en que se enuncia esta defensa del "valor plástico intrínseco" de las obras (palabras que, creemos, pertenecen a Juan Ríos) sean tan similares a las palabras que utiliza, años después, Emilio A. Westphalen ${ }^{12}$ (1968) cuando rememora la importancia de Ricardo Grau (quizá el pintor más reivindicado por Nuestro Tiempo) en la pintura peruana y el rol que jugó en la década de 1940:

12 Poeta, ensayista e importante animador cultural, Emilio Adolfo Westphalen (1911-2001) fue director de las revistas El uso de la palabra (1939), Las Moradas (1947-1949), Revista Peruana de Cultura (1963-1970) y Amaru (1967-1971). En todas estas publicaciones abogó siempre por la hegemonía de un arte independiente, que no estuviera jamás gobernado por consignas políticas, ataduras geográficas o representaciones localistas. 
[...] su hazaña principal ha consistido en batallar porque se reconocieran que los valores en que se basa la apreciación de un cuadro son los mismos que éste nos propone y no los que pretendemos añadirle con propósito anecdótico, literario o sentimental; es decir, a la pintura hay que amarla por sí misma, extraña amalgama de realidad e imaginación, objeto inútil y necesario como todo lo que el hombre intenta para explicarse y justificarse (p. 73).

Lo anecdótico, lo literario, lo pintoresco o lo imitativo conformarán criterios ya anacrónicos para apreciar el arte. En ese sentido, solo la composición del cuadro, la imaginación creativa y la representación espiritual del artista serán los factores que determinarán la originalidad de una obra. Además, debemos recordar que nos encontramos en un ambiente que ya reconoce en el realismo socialista (el indigenismo y otros programas artísticos impregnados de ideología política) un modelo agotado y que, por el contrario, demanda que la pintura se encuentre direccionada por un trabajo serio en la técnica y los problemas netamente plásticos. La demanda por un cambio en el arte peruano ya se observaba en proyectos como la primera exposición surrealista en Lima (organizada por César Moro en la academia Alcedo en mayo de 1935), el I Salón de Independientes (organizado en enero de 1937 en la Escuela de Bellas Artes) o las ideas expuestas en la revista El uso de la palabra (dirigida por César Moro y Emilio A. Westphalen), así como también en las ideas defendidas por críticos como Carlos Raygada, Luis Fernández Prada y Raúl María Pereyra, quienes desarrollaron su labor en periódicos y revistas de la época.

Regresando a la exposición, creemos que esta resulta un hecho significativo, por cuanto no solo se trata de la batalla por el arte independiente que Nuestro Tiempo busca impulsar, sino que demuestra que esta revista se comprometió también con la producción cultural de la ciudad al idear, organizar y preparar una exposición con las obras de pintores como Jorge Vinatea Reinoso, Carlos Quizpez Asín, Ricardo Grau, Juan Manuel Ugarte Eléspuru, Federico Reinoso, Sabino Springett y Sérvulo Gutiérrez, lista de artistas cuya factura estética es, desde luego, el camino del arte moderno en el Perú. Nuestro Tiempo reflexiona, pero también modela y propone, con lo cual podemos afirmar que deviene en una plataforma cultural y agente de canonización de artistas plásticos en la Lima de los años cuarenta. ${ }^{13}$

Ahora, la producción cultural de Nuestro Tiempo no solo desea circunscribirse a las exposiciones de pintura, sino que pretende también iniciar la edición de libros. Se anuncia, así, la próxima aparición de los libros 20 poemas de Enrique Solari, Hacia el reino de los Sciris de César Vallejo y La Pintura Contemporánea en el Perú de Juan Ríos. La publicación de estos volúmenes, en tanto responsabilidad de Nuestro Tiempo, no se llegó a concretar, ya que la revista, según sabemos, culminó su trayectoria luego de una tercera entrega, solo cuatro meses después de anunciar la aparición de las obras mencionadas más arriba. Lo que sí conocemos es que dos fragmentos del último de los títulos mencionados fue publicado en las páginas de la revista: un avance de La pintura contemporánea en el Perú (1946) de Juan Ríos, personaje sobre el que quisiéramos desarrollar algunas ideas a continuación.

Consideramos que la presencia de Juan Ríos Rey (1914-1991) constituye un factor fundamental en el trayecto vital de Nuestro Tiempo. Ensayista, dramaturgo, poeta y crítico

13 Un ejemplo de esto es cómo, en un artículo sobre los nuevos pintores en el Perú, una columnista de nombre Claudine (1944, p. 6), dirige la atención del lector hacia la consigna de un arte sin programa ni ataduras, un arte que puede denominarse independiente y al mismo tiempo contemporáneo: "En medio de esta animación, que hace cada vez más interesante la vida en Lima, pueden percibirse las nuevas direcciones que va tomando la pintura peruana contemporánea.

Esta nueva orientación parece cristalizarse en un grupo de artistas quienes, lejos de querer reunirse bajo una etiqueta fija, o encerrarse en definiciones inmutables, siempre limitadas y estrechas en arte, siguen el camino de su propia sensibilidad y se ven, sin embargo, reunidos por una común inquietud: la búsqueda de un arte verdaderamente actual." 
de arte, Ríos se muestra como el protagonista de esta publicación. Aunque su nombre apareciera solo como miembro del consejo de redacción, su presencia escritural en las páginas de la revista le confieren gran parte de la responsabilidad de la misma. ${ }^{14}$ Mientras que Xavier Abril se ocupa más de los temas literarios y Hernández de Aguiero de la esfera política o sociológica, Ríos se decanta casi principalmente por la discusión sobre arte en toda la revista. Es uno de los promotores del "Primer Salón de Pintura de Nuestro Tiempo" (ya mencionado anteriormente); reseña libros y revistas; escribe sobre la situación política mundial (específicamente, sobre la Segunda Guerra Mundial); comenta exposiciones de arte e, incluso, en el primer número de Nuestro Tiempo, ofrece un amplio comentario en siete páginas a doble columna en las que reseña y comenta varias exposiciones de arte montadas en Lima entre 1940 y $1943 . .^{15}$

Es en el segundo número de Nuestro Tiempo donde aparece por primera vez un fragmento del libro La Pintura contemporánea en el Perú, publicación que, en conjunto con La poesía contemporánea del Perú (preparado y editado por Jorge Eduardo Eielson, Sebastián Salazar Bondy y Javier Sologuren), resultará fundamental en la modernización del imaginario artístico y

14 En su libro Mi vida propia. Diario personal 1940-1991, Juan Ríos ofrece algunas opiniones que tiene sobre su propia revista, y que parece solo querer reservar a una esfera personal, como lo es un diario íntimo. En una entrada correspondiente al 15 de enero de 1944, Ríos (1993) confiesa que, en su opinión, su revista evidencia una presentación y tipografía rudimentarias, casi de naturaleza escolar; asimismo, comenta los aciertos y falencias de algunos artículos, además de afirmar que el texto editorial es de su autoría (p. 58).

15 El artículo se titula "Principales Exposiciones realizadas en Lima durante la segunda guerra mundial" y ofrece una nota sobre sobre cada una de las siguientes exposiciones:

1) Exposición de Victorio Macho (1940)

2) Exposición de la pintura contemporánea norteamericana (1941)

3) El Primer Salón Municipal (1943)

4) El Salón de la Exposición Amazónica (1943)

5) La exposición de Teodoro Núñez Ureta (1943)

6) La exposición de Enrique Domingo Barreda (1943)

7) La exposición de Arte Contemporáneo del Hemisferio Occidental (1943)

8) La exposición de Arte Gráfico del Hemisferio Occidental (1943)

Consideramos que este conjunto de reseñas constituye un documento valioso para el estudio del desempeño de la ciudad en lo que se refiere a las exposiciones artísticas de los primeros años de esa década. 
literario del Perú. Ambos libros aparecen en 1946 y son publicados por la editorial Cultura Antártica, cuyo director literario era Raúl Porras Barrenechea. Comprender el vínculo de ambos proyectos es decisivo para entender el debate y la orientación que se desea para la poesía y la pintura. En su libro, Ríos (1946) llega a afirmar que, en el Perú "no existe todavía una Escuela Nacional de Pintura" (p. 16) y que, aunque tanto la pintura académica como la escuela indigenista intentaron sentar las bases de un arte pictórico peruano, no lo lograron, con lo que los únicos que acaso se han acercado a la renovación del arte peruano son los independientes:

Los pintores independientes, a su vez, reaccionan contra las dos tendencias anteriores. Interesados en exclusivos problemas plásticos, y habiendo vivido, en su mayor parte, en Europa, su arte no tiene raíces nacionales, pero responde, más que el Académico y el Indigenista, al espíritu de nuestro Tiempo (Ríos, 1946, p. 18).

A pesar de algunas diferencias señaladas por investigadores como Luis Rebaza Soraluz, lo cierto es que La pintura contemporánea en el Perú y La poesía contemporánea del Perú constituyen dos proyectos intelectuales que dialogan entre sí e intentan permear el concepto de creación y obra artística con un carácter moderno, en el que las ideologías (la política) se encuentren apartadas de la creación per se, y donde el aspecto más importante sea el principio de libertad del artista, así como la composición plástica (en el caso de la pintura) o los valores puramente literarios o poéticos (para el caso de la poesía). Es por eso que, al ser el primer espacio editorial que publica parte del libro La pintura contemporánea del Perú, Nuestro Tiempo deviene una "plataforma modernizadora" (Rebaza Soraluz) que, en el terreno de la política, el arte o la literatura, busca renovar el imaginario de la ciudad. Es en estos años que aparecen innumerables plataformas modernizadoras, ${ }^{16}$ como la Alianza de Intelectuales Antifascistas, el diario La Nación, el Frente Democrático Nacional, la Editorial Cultura Antártica, la Peña Pancho Fierro, la Galería de Lima, la Agrupación Espacio, y revistas como Historia (1943-1945), Las Moradas (1947-1949), El Correo de Ultramar (1947) y Mar del Sur (1948-1953). Siguiendo esa orientación, proponemos a Nuestro Tiempo como una plataforma modernizadora del arte pictórico peruano y un agente de renovación cultural y de resistencia frente al orden político imperante en esos años.

La defensa de la cultura, como lo indica el subtítulo de la revista, es una consigna que implica, también, una adhesión a los ideales de libertad y un rechazo firme a toda forma de opresión y práctica autoritaria. Por eso, en su ensayo El Problema de la Anticultura, publicado en el número 1, Juan Ríos (1944) sostiene lo siguiente:

[...] con el Nacional Socialismo, surge por primera vez en la Historia, la amenaza precisa de la Anticultura. Los bárbaros, por carecer de Civilización, estaban predispuestos a adoptar la de los países conquistados. La Alemania Fascista representa un tipo de Cultura especial: la Anticultura (p. 38).

El ensayo citado no supone, es cierto, una disquisición profunda sobre la naturaleza del concepto "cultura", pero sí lo encontramos relevante en tanto constituye una señal de Nuestro Tiempo como plataforma de resistencia cívica frente al peligro de las ideologías

16 Sobre la definición y desarrollo de algunas plataformas modernizadoras en este periodo, sugerimos la lectura de nuestro estudio "Plataformas modernizadoras en el periodo de José Luis Bustamante y Rivero (1945-1948): revistas y proyectos intelectuales en una Lima democrática”, artículo publicado en Tesis. Revista de Investigación de la Unidad de Posgrado de la Facultad de Letras y Ciencias Humanas de la UNMSM. https:// revistasinvestigacion.unmsm.edu.pe/index.php/tesis/article/view/18824 
guna vez, y, sin quererlo, definió a su patria. Porque, mientras la gloria de la mayoría de las naciones está en sus empresas victoriosas, en sus prácticos triunfos políticos, la grandeza de Alemania se encuentra, quizás,

Los redactores de "Nuestro Tiempo" manifestamos nuestra firme adhesión a quienes, en nombre de la Democracia y la Dignidad del Hombre, han solicitado la derogación de la Ley de Imprenta y de otras Leyes Especiales. cerx

Imagen 6. Sección correspondiente a la manifestación que hace Nuestro Tiempo respecto a la situación de la libertad de prensa en el Perú. Nuestro Tiempo. Número 1. Enero de 1944. Página 38.

autoritarias (los totalitarismos europeos). ${ }^{17}$ Otra prueba de esto es una breve nota de manifiesto por la ley de imprenta aún vigente en esos años: "Los redactores de Nuestro Tiempo manifestamos nuestra firme adhesión a quienes, en nombre de la Democracia y la Dignidad del Hombre, han solicitado la derogación de la Ley de Imprenta y de otras Leyes Especiales.” (Nuestro Tiempo, 1944c, p. 38) Comentarios como este pueden encontrarse en otras publicaciones culturales de la época, como Historia (1943-1945) de Jorge Basadre:

Publicado el decreto que convoca a elecciones generales para el 10 de junio próximo, HISTORIA deplora el hecho de que el Congreso se clausurara sin dar una nueva ley de imprenta y una nueva ley electoral; afirma una vez más su convicción de que él Perú necesita un régimen de libertad con responsabilidad sobre los principios de la estabilidad, de la renovación y de las reformas sociales; y expresa la esperanza de que el futuro inmediato del país esté en manos nó de la oligarquía, sino que ingrese a un derrotero progresista bajo una administración con fuertes bases populares, al servicio del pueblo y por la Patria y que reúna el triple requisito de la técnica, de la moralidad y de la capacidad para planificar con lucidez y coherencia y ejecutar con decisión.

Lima, $1 .^{\circ}$ de diciembre de 1944 (Historia, 1944, p. 448)

17 No deja de ser interesante anotar que, mientras Nuestro Tiempo defiende un arte pictórico libre y desideologizado, publica, al mismo tiempo, poemas políticos de evidente connotación comunista, como "Oda al ejército soviético" de Juan Ríos. Esta contradicción puede explicarse acaso por el enérgico entusiasmo que la revista despierta a sus editores, la mayoría de ellos vinculados al mundo de las artes plásticas, pero que, en el ámbito de la poesía, no presentan el mismo dominio. Podemos indicar, por ejemplo, el caso de la traducción y publicación de un poema de André Breton en el tercer número de Nuestro Tiempo, que recibe una ácida crítica de Emilio A. Westphalen. El ensayista y poeta responde en el diario La Prensa con un artículo implacable en el que critica con dureza las falencias de la traducción realizada. Su texto, además, condena el desconocimiento de los editores para estas tareas y se mofa, indirectamente, de los poemas de tema político publicados en la revista (Westphalen, 1944, p. 6). 
El que se produzca un proceso de elecciones con igualdad de oportunidades no era, desafortunadamente, una posibilidad cercana si es que existía todavía un veto a la prensa libre. Es por eso que, en varios casos, las críticas al poder eran concebidas en espacios pequeños y ligados a grupos intelectuales, artísticos o literarios, cuyas voces podían escucharse en proyectos editoriales como Historia o Nuestro Tiempo. Ambas revistas, como vemos, están preocupadas por la situación política del país y el restrictivo marco legal que amordaza a los medios de prensa. Ello nos lleva, por supuesto, a confirmar el importante rol que cumplió esta revista en el ámbito cultural de Lima durante el primer semestre de 1944. Quizá por eso, Fernando de Szyszlo (2017) la recuerda como una revista valiosa en su apoyo al arte independiente y su rechazo al indigenismo (p. 71), mientras que Peruanidad, ${ }^{18}$ revista editada por el Estado peruano, la destaca como una de las publicaciones recientes que, en el ámbito de las artes, ha aparecido en Lima (Oliva, 1944, p. 1303). Del mismo modo, Juan Ríos (1993), en su diario personal, anota los enconos y enemistades que la revista le acarreó con otros periodistas e intelectuales, suceso que, fuera del comentario anecdótico, reconfirma el diálogo y debate que Nuestro Tiempo entabla con el entorno político y cultural de la ciudad.

18 Peruanidad. Órgano Antológico del Pensamiento Nacional (1941-1946), revista bimensual editada por la Dirección de Prensa y Propaganda del Ministerio de Gobierno. Esta dirección estatal fue creada por el Gobierno de Prado, con el fin de alentar la cultura del país y presentar un órgano del pensamiento nacional. Se trató principalmente de una revista que recogía artículos, ensayos y creaciones literarias ya publicadas, pero también presentaba textos inéditos. Entre los autores presentados estuvieron Martín Adán, Jorge Basadre, José Galvez, Emilio Harth-Terré, Luis E. Valcarcel, Francisco Tudela y Varela y Pablo Neruda. 


\section{Referencias bibliográficas}

Claudine. (1944). Aspectos de la nueva pintura en el Perú. Nuestro Tiempo, 1, pp. 6-9.

Contreras, C. y Cueto, M. (2013). Historia del Perú contemporáneo. Desde las luchas por la Independencia hasta el presente. Lima: IEP, PUCP, Universidad del Pacífico.

Cotler, J. (1987). Clases, Estado y Nación en el Perú. Lima: Instituto de Estudios Peruanos.

Gargurevich, J. (1991). Historia de la prensa peruana (1594-1990). Lima: La Voz Editores.

Historia. (1944, octubre-diciembre). "Ante el porvenir del Perú". En: Historia, 8, p. 448.

Lauer, M. (1976). Introducción a la pintura peruana del siglo XX. Lima: Mosca Azul Editores.

Majluf, N. (2004). "La batalla por el arte moderno". En: Enciclopedia Temática del Perú. Arte, pp. 73-80. Lima: Empresa Editora El Comercio S.A.

Olivas, A. (1944). "Las revistas y periódicos aparecidos en 1943”. En: Peruanidad. Órgano Antológico del Pensamiento Nacional, 16, pp. 1303-1305.

Nuestro Tiempo. (1944a, enero). "Nuestro Tiempo". En: Nuestro Tiempo, 1, p. 1.

Nuestro Tiempo. (1944b). "Primer Salón de Pintura de "Nuestro Tiempo"”. En: Nuestro Tiempo, 1, pp. 10-11.

Nuestro Tiempo. (1944c). "La ley de Imprenta y otras leyes especiales". En: Nuestro Tiempo, 1, p. 38.

Núñez, E. (1994). Panorama actual de la poesía peruana. Lima: "Comisión Centenario de César Vallejo" UNMSM / Ediciones Santiago Aguilar.
Pantigoso, M. (1998). "La generación literaria del 30-36". En I Encuentro Internacional de Peruanistas. Estado de los estudios históricosociales sobre el Perú a fines del siglo XX. Tomo II, pp. 471-492. Lima: Universidad de Lima.

Rebaza Soraluz, L. (2017). De ultramodernidades y sus contemporáneos. Lima: Fondo de Cultura Económica.

Ríos, J. (1946). La pintura contemporánea en el Perú. Lima: Cultura Antártica.

Ríos, J. (1993). Sobre mi vida propia. Diario 1940-1991. Lima: Juan Ríos, SUC.

Ríos, J. (1944). "El Problema de la Anticultura”. En: Nuestro Tiempo, 1, pp. 38-39.

Saco, C. (1944). "Opinión de Carmen Saco”. En: Nuestro Tiempo, 2, p. 4.

Szyszlo, F. (2016). La vida sin dueño. Memorias. Lima: Alfaguara.

Ugarte Eléspuru, J. (1944, enero). “Opinión de Juan Manuel Ugarte Eléspuru”. En: Nuestro Tiempo, 1, p. 5.

Westphalen, E. (1968). "Ricardo Grau, pintor". En: Amaru, 5, p. 73.

Westphalen, E. (1944). "La traducción de un poema de André Breton”. En: La Prensa, 6.

Recibido el 1 de septiembre de 2020 Aceptado el 16 de septiembre de 2020 